Paradigms of Media Power

Des Freedman, Goldsmiths, University of London

Department of Media and Communications, Goldsmiths, University of London, New Cross, London SE14 6NW, UK

"This is the peer reviewed version of the following article: Freedman, Des (D. J.). 2015. Paradigms of Media Power. Communication, Culture \& Critique, 8(2), pp. 273-289. ISSN 17531929 which has been published in final form at $10.1111 / \mathrm{cccr} .12081$ This article may be used for non-commercial purposes in accordance with Wiley Terms and Conditions for Self-Archiving." 


\begin{abstract}
Media power is a crucial, although often taken for granted, concept. Does it express the economic impact of the industry, the political influence of particular 'media moguls' or the media's capacity to modify attitudes and beliefs? Does it refer to the ability of media to provide state or corporate actors with a valuable tool to assert their own dominance or to the diffusion of symbolic resources? Are we to believe that the media are increasingly the locus of power or that they constitute the space where power is decided'? In order to address this dilemma, this article identifies four paradigms — consensus, chaos, control and contradiction — that best express established ways of conceptualizing the flows and relationships related to media power.
\end{abstract} Keywords: power, contradiction, consensus, chaos, control, political economy, pluralism. 


\section{Paradigms of Media Power}

\section{A Definition of Media Power}

There is an emerging, and healthy, public debate about the definition and implications of media power. From Mexico, where young people have taken to the streets to protest at the partisan coverage of the two main television networks, to the UK, where the Leveson Inquiry has daily revealed the intimate details of collusive relationships between top politicians, media executives and police, the behaviour of media corporations and executives has come under increasing scrutiny. In particular, the issue of concentrated media power - the grip of large media businesses over public discourse - is starting to preoccupy not just politicians, civil servants and activists, but ordinary citizens concerned about the ability of communication conglomerates to stifle and distort wider democratic processes. Media power, as exercised by News Corp, Globo, Disney or Google, is seen to be disturbing precisely because it hands definitional, analytical and interpretive authority to unelected organizations and undermines the ability of citizens freely to acquire and exchange the material necessary to make informed decisions about public life. The media's political economy, in other words, gives them their privileged position in the world (McChesney, 2000; Mosco, 2009).

But what sort of power does this refer to, particularly in the context of the classic tension between theories of power that stress domination and subordination and those that emphasise power in terms of the ability to structure action and outcomes (see Scott, 2001)? While accepting that the power of the media-institutions, channels, texts and practices that rely above all on symbolic interactions (Thompson, 1995) — needs to be understood both in its productive and legitimating roles, this article adopts Manuel Castells' definition of power as referring to 'the relational capacity that enables a social actor to influence asymmetrically the decisions of other 
social actor(s) in ways that favor the empowered actor's will, interests and values' (Castells, 2009, p. 10). It further draws on Joseph Turow's argument that power involves 'the use of resources by one organization to gain compliance by another organization' (Turow, 1992, p. 24) and his emphasis on the interconnections between the 'power roles' embedded within the communications process and those of society as a whole. This means that the economic, political, technological and cultural dimensions of media power are not insulated from but reinforce each other in their application to specific cases.

Media power refers, therefore, to the relationships-between actors, institutional structures and contexts - that organize the allocation of the symbolic resources necessary to structure our knowledge about, and by extension our capacity to intervene in, the world around us. The crucial point here is that these relationships are situated in an environment in which access to media power - as with access to all kinds of resources at institutional and societal levels, including health, education and employment—is fundamentally unequal and reflects structural disparities of power in wider society. Media power is both a consequence of and, increasingly, a precondition for continuing, and stratified, processes of social reproduction. It is not traceable to a single source (despite the undoubted impact of a Murdoch or a Berlusconi); it does not 'belong' to Hollywood, Silicon Valley, Madison Avenue or what used to be known as Fleet Street (although it is most certainly mobilized in all those contexts); it is not articulated solely at the textual level and neither does it emerge spontaneously out of the communicative interactions of ordinary people (even though many people may claim to be 'empowered' by their use of media technologies). It is neither about gently persuading nor forcibly coercing individuals to do things they would otherwise choose not to do but about the material co- 
ordination of flows of information, communication and culture such that persuasion and coercion, as well as expression and interpretation, are most effectively able to take place.

In recognition of this relational conception of media power, I want to identify four paradigms - of consensus, chaos, control and contradiction-within which these different dimensions of media power co-exist but where each of which theorizes the play of media power in quite different ways. These are perspectives, in other words, that map not simply how media power 'works' but how one might conceive of it as a social process in its own right. As with any conceptual model, it is open to challenge - there may be additional paradigms, theorists may belong in more than one category, they may have been put into the wrong category or perhaps there are simply too many connections between each of the categories to make them analytically meaningful—but I believe nevertheless that it will help to clarify what is at stake in theorizing media power and therefore to develop a sufficiently robust analytical model both to understand and democratize the relationships to which it refers. The model is not intended to be a simple literature review but a more ambitious reframing of how we might approach the subjects and objects of media power.

Paradigms are useful ways of organizing together discrete elements into theoretical frameworks in order to analyze social phenomena; they are not naturally occurring categories but purposeful ways of ordering the world so as better to make sense of it (Sparks, 2007, pp. 15-17). As such, they map quite closely onto pre-existing categories of media scholarship where the consensus paradigm may be considered to relate to liberal pluralist communication studies, the chaos paradigm to fan studies and cultural studies, the control paradigm to media political economy, and the contradiction paradigm to critical media industry studies and participatory perspectives. However, specific 'disciplinary' approaches to media analysis should not be seen 
as homogeneous nor reduced to a particular orientation, not least in their attitude towards power. The four paradigms discussed in this article, while also not free of internal distinctions and ambiguities, nevertheless provide a more focused approach to questions of power and allow us better to examine the relationships between the economic, political, technological and cultural forces that shape the dynamics of media power as they operate, albeit in quite specific ways, across different genres and platforms.

\section{Consensus}

The consensus paradigm relates to a long-standing and highly influential notion of power that, in advanced liberal democracies, power is widely distributed, pluralistically organized and contributes to a relatively stable social arrangement. Responding to criticism that American society in the mid-twentieth century was dominated by a military, political and financial elite (Mills, 1959 [1956]), pluralists argued that US politics was instead a competitive arena in which different interests vied for power and influence but in which there was no single dominant voice, no undue concentration of power. In Robert Dahl's study of the political system of New Haven, Connecticut, Who Governs?, politics is dominated by coalitions, by rival groups of actors and interests, none of whom could be said to exercise complete control. According to Dahl, 'there was no clear center of dominant influence in the [political] order. No single group of unified leaders possessed enough influence to impose a solution' (2005 [1961], p. 198), certainly not the economic or social 'notables' who had only a limited and shifting impact on New Haven politics. Pluralist politics, argues Dahl, is notable for its 'dispersion of political resources', the 'disappearance of elite rule' (2005, pp. 85-86), and the emergence of polyarchy, a benign mode of democratic politics. 
Yet, despite the multiplicity of beliefs and the variety of channels through which to mobilize these beliefs, a degree of mutual understanding and harmony was still evident to Dahl inside American society. This was not imposed by the 'notables' nor was it spontaneously present in the minds of citizens; instead, members of the political class and the bulk of citizens are engaged in an ongoing dialogue that 'generates enough agreement on rules and norms so as to permit the system to operate' $(2005$, p. 316). The consensus reached is not permanent and nor is it particularly stable but the process of consensus-building is nevertheless vital to the functioning of American democracy. Consensus, concludes Dahl (2005, p. 316) 'is not at all a static and unchanging attribute of citizens. It is a variable element in a complex and more or less continuous process.'

This conception of consensus has long underpinned pluralist arguments concerning the integrative function of the free press as well as the exercise of sovereign power. Dahl acknowledges in Who Governs? the rather modest role of newspapers in fostering pluralism but perhaps the most famous expression of consensus in relation to media power are the rationales for media performance that are proposed in Four Theories of the Press (Siebert, Peterson and Schramm 1963 [1956]) to describe the American and British media systems. This remains the classic exposition of liberal advocacy of the 'freedom of the press' primarily composed of a 'libertarian' approach where newspapers are seen as 'a partner in the search for truth' but where '[t]ruth is no longer conceived as the property of power' $(1963, \mathrm{p} .3)$. The libertarian model was modified in the twentieth century to deal with the growing permeation of society by electronic media and a new 'social responsibility' model emerged reflecting the view 'that the power and near monopoly position of the media impose on them an obligation to be socially responsible' (1963, p. 5). Both rationales, however, were predicated on an unyielding faith in market forces to 
nurture media systems that informed and entertained audiences, that were based on professional values of independence and impartiality and that provided a necessary check on government power. A market-driven media is, from this perspective, one of the guarantors of a pluralist consensus.

This approach resonates in more recent accounts of the democratic role of the media. For example, in Dayan and Katz's notion of integrative 'media events' (Dayan and Katz, 1994)— ceremonial coverage of 'unique' public occasions like state funerals, major sporting events, scandals and political earthquakes_-audiences are enthralled and transformed by the live coverage of these unprecedented events. 'These broadcasts integrate societies in a collective heartbeat and evoke a renewal of loyalty to the society and its legitimate authority (1994, p. 9). We can even identify the consensual dimension of media power in some non-market structures, for example in accounts of public service broadcasting as an institution that serves to produce cohesive viewing and listening publics with distinctive identities but common interests. For Paddy Scannell, organizations like the BBC 'brought into being a culture in common to whole populations and a shared life of a quite new kind' (1989, p. 138) and they remain a central part of British democratic life. Indeed, he attributes unprecedented generative power to the media: 'What was public life before broadcasting?' he wonders (1989, p. 135).

A consensual media system also requires adequate competition between its different outlets and thus the free interchange of all players in an open market. Media economist Ben Compaine describes the patterns of ownership in the largely commercial US media system as 'extremely democratic' and notes that the media tend 'to be run not to promote an ideology but to seek profit' (2001, p. 4). Private ownership is therefore viewed as a steward of plurality with regulation, mostly confined to the broadcast sector, needed only as a last resort in order to deal 
with specific blockages (for example, monopolies or oligopolies) and to redistribute media power across a wider number of players. Indeed, despite recent moves to liberalize media systems and to roll back curbs on ownership concentration (Freedman, 2008a), there remain restrictions on media ownership and forms of public media in almost all countries. This 'mixed economy' approach reflects the enduring appeal of calls for 'choice' of outlets and 'variety' of media content in contemporary democracies, facilitated by a free market but underwritten by the use of limited state power.

In sum, this consensus paradigm relates to a liberal functionalist perspective on media, described by James Curran as one where the media's role is 'to assist the collective selfrealization, co-ordination, democratic management, social integration and adaptation of society' (Curran, 2002, p. 136). In the light of recent exposures of the illegal and unethical behavior of the press, of desperate attempts to boost ratings at all costs, and of the hypercommercialization and globalization of large parts of the media, this approach may appear better suited to an earlier period of media history. However, even with the emergence of digital technologies and 'empowered' consumers, it is stubbornly resistant to change and remains the default language of policymakers wishing to nurture 'open' and 'competitive' media markets. Indeed, it is precisely this approach — in which economic liberalism is seen to promote individual liberty and democratic pluralism - that underpins the arguments of UK news proprietors seeking to maintain self-regulation in the light of the phone hacking crisis. For example, in one of its many attacks on calls for a new, tougher regulatory regime to promote ethical journalism, Britain's top-selling newspaper, the Sun, opined that: 'Ours may be a rough old trade, sometimes scurrilous and always noisy. But without its freedom to dig dirt, embarrass the great and good, and tell unpalatable truths — and, yes, occasionally get it wrong-British democracy risks grievous 
damage' (Sun, 2012). Despite warnings from theorists like Onora O’Neill (2004, p. 8) that '[a]ccording unrestricted freedom of expression not only to individuals but also to powerful institutions, the media among them, is not necessary for but damaging to democracy', this form of media power continues to be invoked as a vital requirement for free speech and social cohesion.

\section{Chaos}

Recent structural and geopolitical shifts have forced an updating of the some of the foundational elements of pluralist accounts of power. While globalization and digitization have contributed to the erosion of fixed spatial boundaries and the rise of a disembedded and decentralised form of capitalism built on abundance and not scarcity, a range of events-for example, the collapse of Communism, the spread of democratization, the growth of public relations, and the weakening of deference towards elites - have precipitated a new and highly volatile paradigm: cultural chaos (McNair, 2006).

The chaos paradigm is based not on the role of singular factors like class, hierarchy and wealth in sustaining unequal social relations, but on ideological diffusion and structural uncertainty. This reflects the dispersed and 'fluid' properties of power in a digital age. According to McNair (2006, p. 200), power

ebbs and flows between locations and centres, spreading amongst societies along the channels and pathways provided by communication media. Power pools. It evaporates, dilutes and drains away as environmental conditions change. Communication in the medium through which power resources are disseminated, and leaky channels of communication therefore mean less secure power centres. 
Traditional systems of gatekeeping and ideological control have, therefore, largely broken down allowing for more interrogative forms of journalism and a flourishing of perspectives, including even the promotion of radical voices—such as Michael Moore and Naomi Klein — that would previously have been kept to the margins.

The paradigm finds its perfect expression in the collapse of an 'old media' logic in the face of the digital media revolution, a situation in which business models, modes of production and consumption patterns which were relatively stable for many years have now started to break down. We are shifting from being a population of established newspaper readers and viewers of scheduled television programmes to an amorphous group of promiscuous consumers that takes its news from diverse outlets, watches television at times (and on platforms) that suit its convenience and not those of the networks, and generally cannot be relied upon to demonstrate brand loyalty for very long. Bob Garfield describes this as 'The Chaos Scenario' (Garfield, 2009) and argues that we are witnessing a seismic shift in media power relationships.

The first element of The Chaos Scenario...creates an inexorable death spiral, in which the fragmentation of audience and DVR ad skipping lead to an exodus of advertisers, leading in turn to an exodus of capital, leading to a decline in the quality of content, leading to further audience defection, leading to further advertiser defection and so on to oblivion. (2009, p. 38)

Although, judging by the revival of the advertising industry, an overall increase in television viewing and, perhaps most surprisingly, a recent increase in network news audiences in the US (Friedman, 2012), the death of 'old media' is somewhat premature, the enormous growth of social media has clearly contributed to a tremendously uncertain, but no less refreshing, atmosphere of confusion in which power, it is argued, operates in far less hierarchical 
ways - proof, for its advocates, of the ability of forms of technological power to mediate, unsettle or reconstititute social relationships.

It is, of course, far from novel to associate the internet with an ability to unsettle the wider communications environment. Indeed, for many years it was viewed as a rather uncontrollable and energetic toddler who fails to adhere to the more ordered practices of the adult world. Consider the words in 1996 of District Judge Dalzell when throwing out the Communications Decency Act, a highly controversial attempt to regulate obscenity online:

The absence of governmental regulation of Internet content has unquestionably produced a kind of chaos, but as one of the plaintiffs' experts put it with such resonance at the hearing: 'What achieved success was the very chaos that the Internet is. The strength of the Internet is that chaos.' (ACLU vs Reno, 1996)

The internet has since grown from an anarchic toddler to a snarling teenager with the ability still to unsettle everything around it. Larry Downes claims that disruptive technologies like the internet, based on very low transaction costs and virtually infinite capacity, undermine established business practices and that, '[c]onfronted with the weird economics of information, the core principles of public law, private law, and information law are being turned upside down' (Downes, 2009, p. 269).

Not everything is to be welcomed in this brave new world but, generally speaking, theories of chaos are seen to express more adequately the fractured and decentralized forms of media power facilitated by digital technologies. Jeff Jarvis describes this as a 'power shift' (2009, p. 11) in which 'the shift from mass [to niche] is really a shift of power from top to bottom, center to edge, them to us' (2009, p. 67). Wired editor Chris Anderson makes a similar point about what he sees as an 'inversion of power' (2009, p. 99) from traditional manufacturers 
and advertisers who are rapidly losing control to newly empowered audiences: 'The collective now controls the message' (2009, p. 99). According to Anderson, we are seeing the transformation of power from label to band, publisher to author, price to free, 'watercooler' moments to dispersed sharing, mass to niche and rigid to elastic while, for Tapscott and Williams in their description of 'Wikinomics', digital 'weapons of mass collaboration' are 'ushering us toward a world where knowledge, power, and productive capability will be more dispersed than at any time in our history' (2008, p. 12).

This corresponds to McNair's conception of a far more fluid social and ideological environment in which traditional mechanisms for ensuring compliance have broken down under the impact both of communicative abundance as well as an increasing unwillingness to 'tow the line'. This has significant political consequences as, for Henry Jenkins, the process of convergence makes it much harder for elites to impose their authority. He contrasts 'old media's' 'power to marginalize' with today's bottom-up 'power to negate' $(2006$, p. 278) that is facilitated by new peer-to-peer networks, characterized by 'prosumption' and underpinned by a collapse of deference. 'Democracy has always been a messy business' he argues, but today's 'politics of parody', in which citizens use digital tools in creative and autonomous ways to express their cynicism towards 'official politics', is a perfectly logical response to the changing dynamics of authority (2006, p. 293). The most dramatic illustration of this view of dispersed media powerand of the interconnections between political, economic and technological contexts-is to be found in claims made about the 'revolutionary' role of social media in the Arab Spring of 2011, the emergence of 'Twitter Revolutions' and the rise of networked protest that culminated in the Occupy movement (Mason, 2012). Indeed, Manuel Castells has famously described this form of protest as 'media counterpower' (2009). 
In his view of power as a highly volatile and diffuse phenomenon, McNair appears to oscillate between a Foucauldian approach, where power is seen as productive and all-pervasive, and a 'new economy' version of earlier pluralist accounts where, for example, Cater writes about the 'mobile and transitory' nature of power in highly segmented decision-making situations (1965, p. 4) just as Freeman (1965, p. 25) highlights the 'complex and pluralistic committee matrix within which so many decisions are reached in a decentralized fashion.' Moreover, McNair admits that the chaos paradigm is not immune from the influence of powerful gatekeepers in the sense that key actors remain determined to stamp their authority on the digital world. The problem is that, given digital abundance and ideological fragmentation, they will find it virtually impossible to secure this objective: 'The chaos paradigm does not abolish the desire for control; it focuses on the shrinking media space available for securing it ideologically.' (McNair, 2006, p. 4).

This is an interesting point although just how difficult it is to secure some semblance of order online is up for debate. As the web grows into adulthood, the desire to control it is increasingly evident and the search for order increasingly important. In a situation in which the internet is expected to contribute some \$4.2 trillion to the GDP of the world's 20 biggest economies (Boston Consulting, 2012), it is not surprising that we see attempts to regulate the chaos and to classify the confusion: Google categorizes the web, Wikipedia orders knowledge and Facebook organizes friendships. This is partly a matter of the cyclical nature of technological evolution (Spar, 2001; Wu, 2011) where technologies pass through different stages of development from anarchy and uncertainty through consolidation to the re-establishment of rules and the re-allocation of property rights. It is also, however, evidence of the profoundly contradictory nature of technological innovation under capitalism - that it benefits the public so 
long as it rewards those who own or control it—and is thus likely not to stay permanently in a state of chaos.

\section{Control}

The underlying pluralism of the consensus and chaos paradigms has triggered responses from theorists who believe that, far from achieving social integration, providing a 'neutral' window on the world or fostering the flourishing of diverse voices, there is such a thing as a 'dominant media' bloc that uses its control over symbolic resources to naturalize hegemonic ideas and to confine public discussion to a narrow and artificially maintained consensus. Brian McNair describes this as the 'control paradigm' and argues (2006, p. 3) that it is:

premised on economic determinacy, whereby ruling elites are presumed to be able to extend their control of economic resources to control of the cultural apparatuses of media, including the means of propaganda and public relations, leading to planned and predictable outcomes such as pro-elite media bias, dominant ideology, even 'brainwashing'.

Whilst this simplifies and caricatures many of the arguments of 'control theorists', it does at least point to some of the mechanisms and impacts that are relevant to this conception of media power: the capturing of media agendas, the commodification of innovation, the deployment of propagandistic techniques, and the circulation of partisan media content aimed at securing compliance with existing social relations. Furthermore, McNair's emphasis on the paradigm is certainly justified considering the influence that it has long exerted over critical academics and audiences and its status as a comprehensive account of the media's failure to perform the task attributed to them by pluralists: to hold power to account. 
However, it vastly exaggerates the homogeneity of those who are said to operate within the paradigm and glosses over important distinctions in a field characterized by a wide range of different perspectives. There are instead many different varieties of what McNair suggests is a fairly uniform approach to media influence on the part of these critical theorists. The 'hardest' edge of the paradigm is best expressed by the propaganda model as developed by Edward Herman and Noam Chomsky in Manufacturing Consent (1988). For them, the mainstream news media are a crucial tool for legitimizing the ideas of the most powerful social actors and for securing consent for their actions: they are the ideological lynchpins of the dominant class and thus a crucial constituent of state power. Through a combination of capitalist property relations and an orientation on profit, the existence of advertising as a key source of capital, the domination of elite sources, sustained attacks on any material that challenges these sources and elite agendas, and the construction of an 'enemy' (whether Communism or Islamism) around which populations (and media agendas) can unite, the mainstream media environment is structured in such a way as to control dissent and steer public action towards the interests of ruling elites. Herman and Chomsky provide detailed empirical analysis of, for example, news media coverage of US interventions in Central America and South-East Asia to make a convincing case that the "societal purpose of the media is to inculcate and defend the economic, social, and political agenda of privileged groups that dominate the domestic society and the state' (1988, p. 298).

David Edwards and David Cromwell of Media Lens, an online group dedicated to correcting the distortions of corporate news, adopt the propaganda model in their rebuttal, primarily, of 'liberal' news outlets (such as the Guardian and the BBC) that, they argue, provide effective cover for what is, overwhelmingly, a partisan and conservative set of interests. 
Interestingly, the problem lies not simply with a corporate media system, described by Edwards and Cromwell as constituting 'a propaganda system for elite interests' (2006, p. 2), but with the individualism and complicity of citizens who refuse to withdraw their support for instruments of class rule that are instead disguised as professional journalistic values. 'Control is maintained', they insist (2006, p. 187), 'not by violence, but by deception, self-deception, and by a mass willingness to subordinate our own thoughts and feelings to notions of "professionalism" and "objectivity".' The media, according to this perspective, are seamlessly integrated into existing structures of power with the result that 'media performance overwhelmingly promotes the views and interests of established power' (2006, p. 178).

It can be argued that the propaganda model constitutes the most hard-hitting section of a broader theoretical movement at the heart of the control paradigm - media political economythat assesses the structuring relationships between economic organization, political contexts, institutional structures, textual possibilities and consumption patterns across media genres (Murdock \& Golding, 2005). For Vincent Mosco, political economy actually 'asks us to concentrate on a specific set of social relations organized around power or the ability to control other people, processes and things, even in the face of resistance' (Mosco, 2009, p. 24). This is a highly productive line of inquiry that attempts to knit together what are often seen as disparate elements of the social world through, above all, privileging the material relations of power that shape the possibilities and contours of media at any one time (Curran, 2002, Garnham, 1990; Golding \& Murdock, 2000; McChesney, 2004; H. Schiller, 1989; D. Schiller, 2007; Smythe, 1981). It is based on the notion, paraphrasing Marx somewhat, that forms of social consciousness correspond to the sum total of capitalist relations of production and has led to illuminating 
critiques of vast areas of media output (see Wasko, Murdock \& Sousa, 2011 for a comprehensive selection).

Of course there are many other approaches within the control paradigm that refute any notion of a uniform, top-down, smooth exercise of power but that does not mean that they escape from its overall logic. For James Carey, power refers to the ability to hegemonize definitions and allocations not of economic phenomena but of reality which he describes as a 'scarce resource' (1992, p. 87): 'Once the blank canvas of the world is portrayed and featured, it is also preempted and restricted' (1992, p. 87). Pierre Bourdieu conceives of symbolic power in terms of its ability to construct reality and endow it with almost magical qualities: the "power of constituting the given through utterances, of making people see and believe, of confirming or transforming the vision of the world and, thereby, action on the world and thus the world itself' (199, p. 170). Even more significantly, Bourdieu sees symbolic power as a highly efficient means of naturalizing certain preferred interpretations of the world and of legitimizing classifications based on those with most access to that power.

Symbols are the instruments par excellence of 'social integration': as instruments of knowledge and communication...they make it possible for there to be a consensus on the meaning of the social world, a consensus which contributes fundamentally to the reproduction of the social order. (1991, p. 166).

This is not the comfortable, democratic consensus discussed by Dahl and his fellow pluralists nor the rather more frazzled and energetic expressions celebrated by chaos theorists but a distilled version of class interests. Whether this process works in relation to the media by including or marginalizing specific perspectives, by shaping and framing social narratives, by influencing what narratives are told in the first place, or by privileging certain individuals with 
greater symbolic resources (and therefore life chances) than others, it seems to me that this is still part of a quite pervasive and critical 'control' paradigm.

\section{Contradiction}

The final paradigm, and the one that most effectively addresses both the relational and material aspects of media power, is a modification of the control paradigm. While it accepts that media power is an interested force, a set of relationships intimately tied to the reproduction of existing relations of power more generally, it seeks to avoid the functionalism with which control theorists are often (and sometimes rightly) associated. Far from media institutions working seamlessly as 'totalitarian structures of power' as recent advocates of the propaganda model have argued (Cromwell \& Edwards, 2006, p. 187), they are rather a series of groups and institutions that, while overwhelmingly tied to powerful interests (and of course the hacking scandal provides an exemplary illustration of this), are not immune from the movements and ideas that circulate in society at any one time and that seek to challenge these power structures (Kumar, 2008). Crucially, as the Italian Marxist, Antonio Gramsci, reminds us, '[a] given socio-historical moment is never homogeneous; on the contrary, it is rich in contradictions' $(1985$, p. 93). What significance does all this have for the study of media power?

To provide a meaningful answer, we need to go back to Marx's conception of contradiction as a key feature of capitalist society. Throughout his writing, Marx combines a tribute to the revolutionary achievements of capitalism with an analysis of why it is systematically unable to make available the full potential of these achievements to its subjects. While the capitalist class has played a 'most revolutionary part' in human history, it has done this, not because of the 'genius' of individual scientists and technologists or the bravery of 
pioneering entrepreneurs, but because it is a system based on a structural need to innovate, expand and accumulate.

The bourgeoisie cannot exist without constantly revolutionising the instruments of production, and thereby the relations of production, and with them the whole relations of society. Conservation of the old modes of production in unaltered form, was, on the contrary, the first condition of existence for all earlier industrial classes. Constant revolutionising of production, uninterrupted disturbance of all social conditions, everlasting uncertainty and agitation distinguish the bourgeois epoch from all earlier ones. (Marx, 1975, p. 36)

Yet, just as Marx was enthralled by capitalism's dynamism, he was appalled by the means by which it is obliged to sustain itself: through destructive competition between different companies, intensive exploitation in order to extract maximum profits, increased alienation as workers are systematically separated from the fruits of their labour, and a disastrous lack of coordination which leads to bouts of overproduction and regular periods of crisis. These processes are for Marx the terrible price to be paid by the majority of people for the wonderful technological advances experienced—albeit unequally—under capitalism.

Marx highlights these contradictory tendencies within capitalism-for example, between the interests of workers and capitalists, between the social relations and productive capacity of the system, between socially useful production and production for exchange and, crucially, between the social aspect of labour and its private appropriation — not as incidental but key both to capitalism's expansion and its demise. As Marx writes in the Grundrisse (1973, p. 77), reflecting on processes that are familiar to many media economists: 
The [capitalist] division of labour results in concentration, co-ordination, co-operation, antagonism of private interests and class interests, competition, the centralization of capital, monopolies and joint stock companies - so many contradictory forms of unity which in turn engenders all these contradictions.

Contradiction, as Ellen Meiskins Wood puts it (2002, p. 278), is therefore 'capitalism's basic operating principle, in a way that is true of no other social form. It is the source, at one and the same time, of both the capitalist system's unique dynamism and its constant self-subversion.' While other theorists identify contradiction as a feature of all social systems, especially in terms of the relationship between humans and nature (for example Giddens, 1979), Wood insists that capitalism alone is predicated on such an inflammable and generative set of tensions.

These contradictions are played out both at the level of institutions and ideas, material as well as symbolic practices. Gramsci, in trying to understand the failure of revolutionary movements of the inter-war period, discussed how there was a battle going on in the minds of ordinary people between what he called 'common sense', ideas generally distilled from the capitalist class, and 'good sense', the formation of a more progressive set of ideas developed in the course of struggling against that class. In particular, he spoke of a dual consciousness that reflects this ongoing battle. The worker

has a practical activity, but has no clear theoretical consciousness of his practical activity, which nonetheless still involves understanding the world in so far as he transforms it. His theoretical consciousness can indeed be historically in opposition to his activity. One might almost say that he has two theoretical consciousnesses (or one contradictory consciousness): one which is implicit in his activity and which really unites him with his fellow-workers in the practical transformation of the real world; and one, superficially 
explicit or verbal, which he has inherited from the past and uncritically absorbed.

(Gramsci, 1971, p. 333)

This is particularly helpful in thinking about the media as a set of institutions and practices that are implicated in the regular advocacy of 'common sense' and the transmission of ideas 'inherited from the past'. But the model also suggests that, when pushed to do by popular mobilizations and mass struggles, the media may be able (albeit in fragile and temporary ways) to articulate strands of 'good sense' and enhance prospects for change (Ytterstad, 2012).

This is especially the case in moments when capitalist hegemony, understood by Gramsci to refer to the various forms of class leadership at any one time, is threatened and unstable. James Carey notes the importance of these interruptions of 'normal' practice: 'The production and reproduction of society is never guaranteed, automatic or mechanical, and the problematics of the phenomenon are often best revealed in moments of conflict and contradiction and in the rare but powerful episodes of coercive violence, social disorder and chaos' (Carey, 1992, p. 110). There have been several examples of how, in recent years, small portions of the mainstream media, despite their frequent involvement in the amplification of powerful voices and reproduction of existing relations, have also provided space to more critical or 'marginal' perspectives (for example in relation to class, gender or ethnicity). For example, in the run-up to the 2003 invasion of Iraq when UK audiences were clearly not satisfied with official explanations and media frames justifying a war, and marched in their millions urging the government not to invade, the popular tabloid title, the Daily Mirror, took up a radical stance in relation to the rush to go to war (Freedman, 2008b). Other examples include sympathetic coverage of the 1997 strike by UPS workers by mainstream media in the US (Kumar, 2008), favourable reporting in the Danish media of environmental campaigning (Ytterstad and Eide, 
2011) or even the recent appearance of an opinion piece by anti-capitalist Occupy representatives in the pages of the business daily Financial Times (Occupy London, 2012). None of these examples occurred because of any inherent pluralism in the mainstream media. The degree to which there are different positions expressed in the media relates to the need, in a competitive market, to address (in however skewed a way) both the interests of different audiences and the existence of conflicts among capitalist elites as well as pressure placed on mainstream media by countervailing forces.

There are, as a result, multiple contradictions within the commercial media: a simultaneous desire for a narrow consensus and yet a structural imperative for difference; a situation in which audiences are treated as commodities but in which they do not always play this role; a tendency for those who work within the media not to rock the boat (for self-protection and advancement) but, in exceptional periods, to do precisely this. We need, therefore, a methodological approach that tackles the mainstream's embedding in elite networks of power but also compensates for the control paradigm's 'inability, or perhaps reluctance, to acknowledge how these contradictions account for instances of creativity, resistance and change' (Havens et al., 2009, p. 238; see also Hesmondhalgh, 2013, p. 45). We need to integrate analysis of the 'quotidian practices and competing goals' of the media industries (Havens et al., 2009, p. 236), with the larger political and economic contexts in which these practices take place and we should neither reduce one to the other nor pretend that micro-level interactions are immune from the impact of the tensions that mark the dynamics of broader social forces.

An approach to the media that focuses on their internal contradictions can highlight not simply the ways in which everything from Hollywood movies to network news and from social media to soap operas to are involved in generating 'common sense', but also how popular 
mobilizations_ — not in the discursive sense discussed by some media scholars (for example Fiske, 1989) — might help to produce forms of 'good sense' inside the media. Recognizing and acting upon these contradictions is necessary, as Mike Wayne puts it (2003, p. 261), 'if we are to avoid sliding into some species of functionalism or pessimism.' This requires an approach to media power that emphasizes structure and agency, contradiction and action, consensus and conflict; an analytical framework that recognizes the existence of unequal power frameworks but acknowledges that they are not forever frozen; and a perspective that takes seriously the activities of producers and audiences while recognizing the existence of uneven consciousness. In short, the contradiction paradigm is needed to compensate for the misplaced optimism of pluralism, the occasional functionalism of the control paradigm and the unwarranted celebrations of the chaos scenario. Media power, according to this perspective, may be comprehensive but it is nevertheless always unstable and contestable.

\section{Conclusion}

Media power is a pervasive but difficult concept. It is too often used as shorthand for the political influence of a particular media mogul or the cultural impact of a specific technology or the affective dimension of a particular text; media power is viewed either as an irrepressible force or a diversion from more substantial threats to democracy and citizenship. This article has instead attempt to develop an understanding of media power as referring to those relationships that help to organize the deployment of the symbolic resources that play a vital role in ensuring social reproduction. These relationships, however, cannot be separated from the material inequalities of society at large: not all audiences are equally desirable to advertisers; not all individuals have the same capacity to start up a publishing venture despite being formally 'free' to do so; not all readers have the same access to editors and owners should they wish to complain 
about something; indeed not all citizens are able to afford the $£ 250,000$ necessary to secure a private dinner with British prime minister David Cameron in order to discuss urgent matters of public policy (Leigh, 2012).

Nick Couldry is absolutely right to argue that media power needs regularly to be reproduced in order to naturalize its authority so as to make its news credible and its fictions relevant and he is completely justified in focusing on the 'universe of beliefs, myths, and practices that allows a highly unequal media system to seem legitimate' (2003, p. 41). Critical media industry scholars are also completely justified in examining how 'particular media texts arise from and reshape midlevel industrial practices' (Havens, Lotz \& Tinic, 2009, p. 237). But media power refers, quite crucially, to more than the cultural processes by which established patterns of media power come to be accepted. It is also about the material relations that underlie this inequality and which then structure the complex operations of media as power holders in their own right. So just as we need to concentrate on the more 'intimate' parts of media powerthe circulation of meaning, the production of texts, the characteristics of media forms - we also need to highlight and evaluate those elements which are crucial in shaping the role and impact of media in public life more generally: questions of ownership and control, policymaking and regulation, corporate strategy and definitions of the public interest.

The paradigms I have provided are, to a greater or lesser extent, coherent frameworks for assessing these interrelationships from a range of different material positions. The consensus approach continues to provide policymakers and industry voices with a 'common sense' narrative about the balance between state and market in contemporary communications systems; the chaos paradigm allows digital optimists better to theorize the non-linearity and multidimensional nature of power flows in a digital and dispersed communications environment 
that challenges the logic of a centralized coordinating structure; and the control paradigm has long provided critics of a market system with a vocabulary with which to identify the democratic deficit caused by private ownership and unaccountable state coordination of the media. Proponents of the contradiction school, while sympathetic to the critiques of the control paradigm, focus on forms of contradictory consciousness together with the instability and contingency of existing forms of media control. Perhaps no single model can do justice to the heterogeneity of media flows and the complexity of power but the contradiction paradigm, with its emphasis on both the constitution of and the cracks in media power provides the most persuasive account of how best to challenge the traditions, institutions and practices that underpin it. 


\section{References}

ACLU vs Reno (1996) 11 June, 96-963. Retrieved from http://www.pas.rochester.edu/ mbanks/CDA/decision/dalzell.html

Anderson, C. (2009 [2006]). The longer long tail: How endless choice is creating unlimited demand. London: Random House Business Books.

Boston Consulting (2012). The internet economy in the G-20: The $\$ 4.2$ trillion growth opportunity. Boston: Boston Consulting.

Bourdieu, P. (1991). Language and symbolic power. Cambridge: Polity.

Carey, J. (1992). Communication as culture: Essays on media and society. London: Routledge.

Castells, M. (2009). Communication power, Oxford: Oxford University Press.

Cater, D. (1965). Power in Washington: A critical look at today's struggle to govern in the U.S.A. London: Collins.

Compaine, B. (2001). The myths of encroaching global media ownership. openDemocracy, 8 November. Retrieved from http://www.opendemocracy.net/mediaglobalmediaownership/article_87.jsp

Couldry, N. (2003). Beyond the Hall of Mirrors? Some Theoretical Reflections on the Global Contestation of Media Power. In N. Couldry \& J. Curran (Eds.) Contesting media power: Alternative media in a networked world (pp, 39-54). Lanham: Rowman \& Littlefield. Curran, J. (2002). Media and power. London: Routledge.

Dahl, R. (2005 [1961]). Who governs?: Democracy and power in an American city (2 $2^{\text {nd }}$ ed.). New Haven: Yale University Press.

Dayan, D. and Katz, E. (1992). Media events: The live broadcasting of history. Cambridge: Harvard University Press. 
Downes, L. (2009). The laws of disruption: Harnessing the new forces that govern life and business in the digital age, New York: Basic Books.

Edwards, D. \& Cromwell, D. (2006). Guardians of power: The myth of the liberal media. London: Pluto.

Fiske, J. (1989). Television culture. London: Routledge.

Freedman, D. (2008a). The politics of media policy. Cambridge: Polity.

Freedman, D (2008b). The Daily Mirror and the war in Iraq. In A. Biressi and H. Nunn (Eds.) The tabloid culture reader (pp. 70-80). Maidenhead: Open University Press.

Friedman,W. (2012). TV News Shows Spike in Viewers, Ratings, mediapost.com, 19 March. Retrieved from http://www.mediapost.com/publications/article/170550/tv-news-showsspike-in-viewers-ratings.html

Garfield, B. (2009). The chaos scenario. Stielstra Publishing.

Giddens, A. (1979). Central problems in social theory: Action, structure and contradiction in social analysis. London: Macmillan.

Garnham, N. (1990). Capitalism and communication. London: Sage.

Golding, P. \& Murdock, G. (2000). Culture, communications and political economy. In J. Curran \& M. Gurevitch (Eds.) Mass media and society ( $3^{\text {rd }}$ ed., pp. 70-92). London: Arnold.

Gramsci, A. (1971). Selections from the prison notebooks. London: Lawrence \& Wishart.

Gramsci, A. (1985). Selections from cultural writings. London: Lawrence \& Wishart.

Havens T., Lotz, A. \& Tinic, S. (2009). Critical Media Industry Studies: A Research Approach. Communication, Culture \& Critique 2, 234-253.

Herman, E. \& Chomsky, N. (1988). Manufacturing consent. New York: Pantheon.

Hesmondhalgh, D. (2013). The cultural industries ( $3^{\text {rd }}$ ed.). London: Sage. 
Jarvis, J. (2009). What would Google do? New York: Collins Business.

Jenkins, H. (2006). Convergence culture. New York: New York University Press.

Kumar, D. (2008). Outside the box: Corporate media, globalization, and the UPS strike. Urbana: University of Illinois Press.

Leigh, D. (2012, March 27). David Cameron admits to private dinners for Tory donors. Guardian, p. 1.

Marx, K. (1963). Selected writings in sociology and social philosophy. Harmondsworth: Penguin.

Marx, K. (1973 [1858]. Grundrisse: foundations of the critique of political economy. London: Allen Lane.

Marx, K. (1975 [1848]). Manifesto of the Communist Party. Peking: Foreign Languages Press. Mason, P. (2012). Why it's kicking off everywhere: The new global revolutions. London: Verso. McChesney, R. (2000). Rich media, poor democracy. New York: New Press.

McNair, B. (2006). Cultural chaos. New York: Routledge.

Miller, D. (2002). Media Power and Class Power: Overplaying Ideology. In L. Panitch and C. Leys (Eds.) Socialist register (pp. 245-264). Woodbridge: Merlin Press.

Mills, C. Wright (1959 [1956]). The power elite. New York: Galaxy.

Mosco, V. (2009). The political economy of communication $\left(2^{\text {nd }}\right.$ ed.). London: Sage.

Murdock, G. \& Golding, P. (2005). Culture, Communications and Political Economy. In J. Curran \& M. Gurevitch (Eds.), Mass media and society. (4 ${ }^{\text {th }}$ ed., pp. 60-83). New York: Hodder Arnold.

Occupy London (2012, January 25). How Hayek helped us to find capitalism's flaws, Financial Times, p.13. 
O’Neill, O. (2004). Rethinking freedom of the press. Dublin: Royal Irish Academy.

Scannell, P. (1989). Public service broadcasting and modern public life, Media Culture and Society, 11(2), 135-166.

Schiller, D. (2007). How to think about information. Urbana: University of Illinois Press.

Schiller, H. (1989). Culture, Inc.: The corporate takeover of public expression. New York: Oxford University Press.

Scott, J. (2001). Power. Cambridge: Polity.

Siebert, F. Peterson, T. \& Schramm, W. (1963 [1956]). Four theories of the press. Chicago: University of Illinois Press.

Smythe, D. (1981). Dependency road: communications, capitalism, consciousness, and Canada. Norwood: Ablex.

Spar, D. (2001). Ruling the waves: Cycles of discovery, chaos and wealth from the compass to the internet. New York: Harcourt.

Sparks, C. (2007). Globalization, development and the mass media. London: Sage.

Sun (2012, October 31). The Sun Says. Sun, p.8.

Thompson, J. (1995). The media and modernity: A social theory of the media. Stanford: Stanford University Press.

Turow, J. (1992). Media systems in society: Understanding industries, strategies, and power. New York: Longman.

Wasko, J., Murdock, G. \& Sousa, H. (2011). The handbook of political economy of communications. Oxford: Blackwell. 
Wayne, M. (2003). Marxism and Media Studies: Key Concepts and Contemporary Trends. London: Pluto.

Wood, E.M. (2002). Contradictions: Only in Capitalism? In L. Panitch \& C. Leys (Eds.), Socialist register (pp. 275-293). Woodbridge : Merlin Press.

Wu, T. (2011). The master switch, New York, Vintage.

Ytterstad, A. (2012). Norwegian climate change policy in the media: Between hegemony and good sense. PhD dissertation. Oslo: University of Oslo.

Ytterstad, A. and Eide, E. (2011). The Tainted Hero: Frames of Domestication in Norwegian Press Representation of the Bali Climate Summit, International Journal of Press/Politics $16(1), 50-74$. 